\title{
Avaliação do Funcionamento de um Simulador de Chuva Pelo Método da Farinha
}

\author{
Miriam de Fátima Carvalho \\ Escola de Engenharia - Universidade Católica do Salvador \\ miriam@ucsal.br \\ Jorge Luis Zegarra Tarqui \\ Departamento de Engenharia Hidráulica e Recursos Hídricos - UFMG \\ jlztarqui@yahoo.com.br \\ Vitor Sousa Silva \\ Programa de Pós-Graduação e Recursos Hídricos e Saneamento Ambiental IPH - UFRGS \\ Vitorsouza22@bol.com.br \\ Bruno Rogério da Hora Lobo \\ Programa de Pós-Graduação em Geotecnia-UNB \\ Bruno.rhl@hotmail.com
}

Recebido: 22/02/11 - revisado: 21/07/11 - aceito: 22/03/12

\section{RESUMO}

Este estudo tem como objetivo avaliar o efeito dos parâmetros de operação pressão de serviço e abertura ajustável da placa do disco de um simulador de chuvas sobre a distribuição do tamanho das gotas e na energia cinética da chuva empregando o método da farinha. Ademais, o artigo descreve de forma detalhada o procedimento experimental com a intenção de propor uma padronização do método. Apesar de trabalhoso, o método da farinha foi considerado adequado para determinação do D50 em diferentes situações de funcionamento de simulador de chuva com bico pressurizado e placa de abertura giratória. Os resultados mostraram que a abertura da placa afeta de forma significativa o diâmetro médio de gotas e que a pressão de serviço tem efeito menor. Comportamento similar foi observado na variação da intensidade da chuva simulada pelo equipamento, no qual a abertura da placa tem papel preponderante.

Palavras-chaves: Chuva simulada; Diâmetro de gota; Energia cinética.

\section{INTRODUÇÃOO}

O impacto das gotas de chuva na superfície do solo tem efeito importante no processo erosivo, pois provoca o destacamento e o salpicamento das partículas, disponibilizando-as para o arraste durante o escoamento superficial. O impacto das gotas e o salpicamento (splash erosion) de partículas podem causar ainda o selamento superficial do solo o que contribui para reduzir a infiltração de água, intensificando o problema da erosão (Alves Sobrinho, 2002). De uma forma geral, este efeito é avaliado através da energia cinética da gota de chuva ao tocar o solo. Segundo Hudson (1995), a energia cinética devido ao impacto da gota de chuva é 256 vezes maior que a energia do escoamento superficial. Guy et al. (1987) sugerem que $85 \%$ dos sedimentos da erosão hídrica têm origem no impacto das gotas de chuva e $15 \%$ restantes são atribuídos ao escoamento superficial.

Inicialmente, a energia cinética era avaliada através da intensidade da chuva (taxa de variação da lâmina d'água com o tempo), como propuseram Wischmeier \& Smith (1958) através da Equação 1, a qual foi convertida para o Sistema Internacional de Unidades, de acordo com Foster et al. (1981). Essa equação tem sido amplamente utilizada, apesar de ter sido obtida para padrões de chuva dos EUA. Wagner \& Massambani (1988) apud Ribeiro 2006 realizaram um estudo dos padrões de chuva da região de São Paulo e propuseram uma equação de energia cinética (Equação 2) que, segundo os auto- 
res, não diferiu significativamente daquela proposta por Wischmeier \& Smith (1958).

$\mathrm{E}_{\mathrm{C}}=0,119+0,0873 \log \mathrm{I}$

$\mathrm{E}_{\mathrm{C}}=0,153+0,0645 \log \mathrm{I}$

em que $\mathrm{E}_{\mathrm{C}}$ é a energia cinética da chuva, em $\mathrm{MJ}$. $h \mathrm{a}^{-1} \cdot \mathrm{mm}^{-1}$; e I é a intensidade de precipitação, em $\mathrm{mm} \cdot \mathrm{h}^{-1}$.

Atualmente, é consenso entre os pesquisadores que o poder erosivo da chuva não é somente em função da quantidade de chuva, mas também de suas características físicas, como tamanho e distribuição das gotas, combinação da massa e velocidade de impacto da gota. Dessa forma, a energia cinética pode ser obtida pela Equação 03, onde m é massa da gota e vé a velocidade de impacto.

A Equação 04 apresenta a energia cinética por unidade de volume de chuva $\left(\mathrm{e}_{\mathrm{c}}, \mathrm{em} \mathrm{J} \cdot \mathrm{m}^{-2}\right.$. $\left.\mathrm{mm}^{-1}\right)$. Onde, $\mathrm{v}_{\mathrm{i}}\left(\mathrm{m} \cdot \mathrm{s}^{-1}\right)$ é a velocidade da gota de chuva, $\mathrm{d}_{\mathrm{i}}(\mathrm{mm})$ é diâmetro das gotas, $\mathrm{n}_{\mathrm{i}} \mathrm{o}$ número de gotas, o subscrito i representa a classe (intervalo) do tamanho de diâmetro e $\mathrm{N}$ é o número total de classes de diâmetro na distribuição das gotas. $O$ termo $\rho$ é a massa específica da gota de chuva (g. $\mathrm{cm}^{-3}$ ) associada a um $\mathrm{mm}$ de chuva.

$\mathrm{E}_{\mathrm{c}}=\frac{1}{2} \mathrm{~m} \cdot \mathrm{v}^{2}$

$e_{c}=\frac{\rho}{2} \cdot \frac{\sum_{i=1}^{N} d_{i}^{3} \cdot v_{i}^{2} \cdot n_{i}}{\sum_{i=1}^{N} d_{i}^{3} \cdot n_{i}}$

A determinação da energia cinética das chuvas naturais (Frontais e Convectivas) requer o estudo da distribuição das gotas e a necessidade de desenvolver simuladores que reproduzam com maior fidelidade as chuvas naturais. O estudo das chuvas naturais e simuladas deve ser realizado de forma conjunta, estabelecendo a importância da chuva natural na escolha do tipo de simulador.

A obtenção da distribuição do tamanho das gotas e velocidade de impacto é tarefa trabalhosa, quer seja para chuvas naturais ou chuvas simuladas, especialmente para o caso de uso de simuladores de chuva dotados de bicos pressurizados. No caso de chuvas naturais existe grande variabilidade temporal e espacial na distribuição do tamanho das gotas dentro de mesmo evento de chuva. No caso de simuladores com bicos pressurizados, devido a pressurização da água, as gotas apresentam velocidade inicial maior do que zero e grande fracionamento em gotas de menores diâmetros, o que dificulta bastante o processo experimental.

O tamanho e distribuição de gotas de chuva naturais ou produzidas em simuladores têm sido determinados por diversos pesquisadores, empregando os mais diferentes métodos, a saber, método do óleo (Eigel \& Moore, 1983), método da mancha (Hall, 1970), método da farinha (Hudson 1964), método disdrômetro (Joss \& Waldvogel, 1969), método do laser óptico (Kincaid et al 1996), dentre outros. A maioria desses métodos necessita de calibração da relação entre volume ou massa de gotas de diâmetros conhecidos com aqueles fabricados em diversos meios.

O método do óleo é baseado na suposição de que gotas de água suspensas em fluído denso viscoso assumem uma forma esférica em virtude da tensão superficial e pressão distribuída sobre elas. As gotas podem ser fabricadas sem alteração de sua forma original e podem ser medidas com microscópico ou em imagem ampliadas (Gunn \& Kinzer, 1949). Segundo Armfield (1998) esta técnica produz bons resultados, com desvio menor que $2 \%$ para gotas menores que $10 \mathrm{mg}$ menor que $0,5 \%$ para gotas de $10.000 \mathrm{mg}$.

O método da mancha consiste em deixar cair gotas de água em papéis marcadores e medir o diâmetro correspondente da mancha impresso no papel. Essa técnica não apresenta bons resultados, pois a mancha pode apresentar deformação por espalhamento de até $14 \%$. Segundo Curvinel et al 1996, a avaliação manual dos diâmetros das gotas era a principal dificuldade na utilização dos métodos da manha e do óleo. Atualmente, o reconhecimento dos diâmetros de forma automatizada tem tornado estas técnicas mais atrativa, rápida e confiável, pois o trabalho tedioso de computar as imagens pode ser realizado por analisadores de imagens e scanners (Attle et al 1980).

O método da farinha, extensivamente revisado e descrito por Hudson (1964), consiste em capturar gotas de água em bandejas contendo uma camada solta de farinha de trigo, que através do contato da água com farinha formam-se grânulos que serão secos e separados em diferentes tamanhos. O método permite medir gotas com diâmetro mínimo de 0,3mm (Kohl, 1974, e Kincaid et al 1996). 
O método do disdrômetro de impacto (Joss e Waldvogel, 1969) emprega um equipamento que transforma o momentum mecânico, devido ao impacto da gota incidente em um cone sensor (de área de $50 \mathrm{~cm}^{2}$ ), em um pulso elétrico. A amplitude do pulso gerado é proporcional ao diâmetro e à velocidade da gota. O instrumento determina a distribuição de tamanho de gotas de chuva através de um espectrômetro eletromecânico gerado. Para Tokay et al 2003 o disdrômetro tem várias deficiências, o equipamento subestima o número de pequenas gotas na chuva forte devido ao "tempo morto" (característica dos sistemas de medição que reflete em atraso na resposta ao sistema de controle), a detecção de gotas menores é também suprimida na presença de ruído de fundo, as gotas maiores do que 5,0-5,5 $\mathrm{mm}$ de diâmetro não podem ser distinguidas, também o aparelho assume que todas as gotas de chuva caem em sua velocidade de queda terminal ignorando a influência do movimento vertical do ar nos resultados da velocidade, induzindo erros no cálculo do tamanho da gota e nos descritores do volume de chuva precipitado.

Segundo Kincaid et al 1996, o método do laser óptico é interessante, pois oferece alta velocidade na coleta de dados quando comparado com os outros métodos e apresenta resultados compatíveis como aqueles produzidos no método da farinha. A desvantagem é que várias gotas atravessando simultaneamente o feixe de laser produz imagem superposta que pode ser interpretada como uma grande gota. Essa superposição pode ser minimizada reduzindo a área de varredura do laser.

Este estudo tem como objetivo avaliar o efeito dos parâmetros de operação, pressão de serviço e abertura ajustável da placa do disco de um simulador de chuvas sobre a distribuição do tamanho das gotas e na energia cinética da chuva empregando o método da farinha. Ademais, o artigo descreve de forma detalhada o procedimento experimental com a intenção de propor uma padronização do método.

\section{PROCEDIMENTO EXPERIMENTAL}

\section{Simulador de chuva}

O simulador de chuva de disco giratório (modelo FEL 3, fabricado pela Armfield) usado neste estudo é composto por uma câmara pulverizadora suportada por estrutura metálica e por acessórios que compreendem reservatório de água, bomba de recalque e painel de controle (Armfield, 1998). $\mathrm{O}$ equipamento funciona através do bombeamento de água do reservatório até a câmara pulverizadora, passando por um registro de gaveta, que permite ajustar a pressão desejada, através do conhecimento da pressão de água que chega ao bocal via manômetro de Bourbon. Logo abaixo do bocal, o jato de água é interceptado por um disco giratório, que tem sua velocidade de rotação ajustada e aferida no painel de controle podendo chegar a $240 \mathrm{rev} . / \mathrm{min}$ e sua abertura podendo variar de $5^{\circ}$ a $40^{\circ}$ de $5^{\circ}$ em $5^{\circ}$, permitindo assim obter variações nas intensidades das precipitações induzidas. A Figura 1 ilustra o simulador de chuvas descrito.

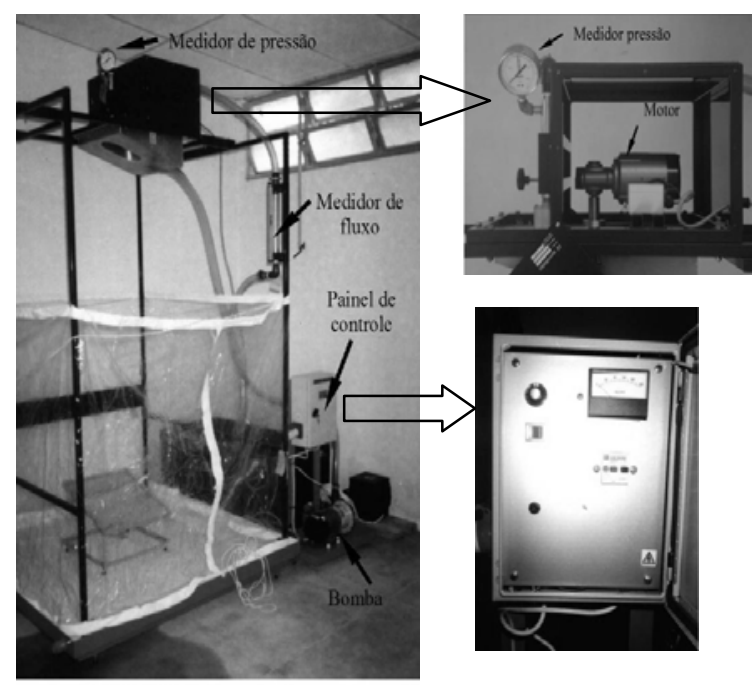

Figura 1 - Simulador de chuva usado.

\section{Método da farinha}

O método da farinha consiste em expor bandejas contendo farinha de trigo, peneirada e não compactada, à precipitação. O contato das gotas com a camada da farinha formará grânulos que em seguida serão secos ao ar, separados por peneiras de diferentes tamanhos e, posteriormente secos em estufa e pesados. Para aplicação desse método duas etapas são necessárias, uma primeira que se refere à obtenção da curva de calibração e a outra se refere á obtenção da distribuição volumétrica das gotas de chuva precipitada. A curva de calibração que expressa a relação entre a massa de água da gota e a massa do grânulo (Mwgota/Mgrânulo) deve ser elaborada previamente, sob as mesmas condições em que serão desenvolvidos os ensaios. Considerando que as gotas apresentam formato esférico, calcula-se o volume ocupado pelas gotas, obtendo assim sua distribuição. Este procedimento permite determinar o diâmetro 
volumétrico médio de gotas, D50, que é o diâmetro médio obtido por $50 \%$ das gotas, esta variável é a que melhor representa a distribuição de gotas de uma precipitação. Para facilidade de aplicação do procedimento experimental são detalhados a seguir os passos a serem seguidos em cada etapa:

a) Curva de calibração: Relação entre massa de água da gota e massa do grânulo (Mwgota/Mgrânulo:

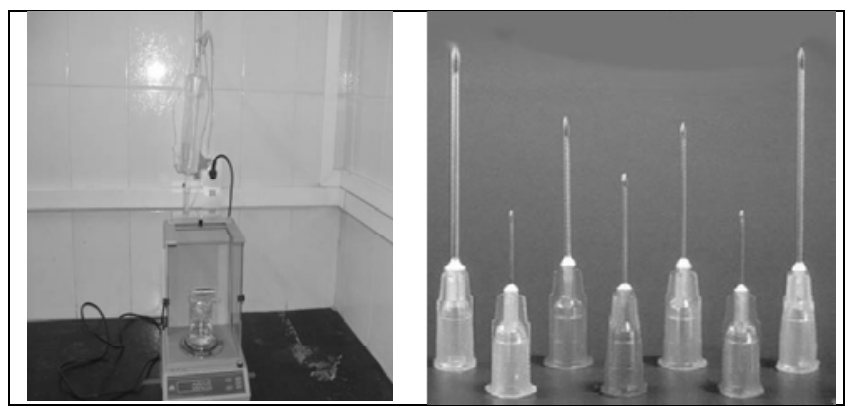

(a)

(b)

Figura 2 - Sistema para obter a massa da gota a partir de agulhas hipodérmicas. a) equipamento de pesagem;

b) conjunto de agulhas hipodérmicas.

Para obter essa relação, inicialmente, foi realizado um experimento para medir a massa de água média contida em gotas produzidas por agulhas hipodérmicas de várias aberturas e por micropipetas. A massa de água da gota foi obtida com a ajuda de um sistema, conforme mostra a Figura 2. Utilizou-se um frasco de soro fisiológico com regulador de gotejamento, balança eletrônica de precisão, becker, água destilada e agulhas hipodérmicas de aberturas variadas. $\mathrm{O}$ frasco de soro cheio de água destilada foi fixado a $40 \mathrm{~cm}$ de altura em relação à balança eletrônica, sendo as agulhas acopladas na mangueira do gotejador. Com o regulador de gotejamento ajustou-se a velocidade de queda das gotas dentro do becker que está posicionado sobre o prato da balança de precisão. Após o gotejamento de cerca de 100 gotas, obteve-se a massa de água total e, em seguida, a massa de água média para cada agulha usada. Para maior representatividade, este ensaio foi repetido três vezes e trabalhou-se com o valor médio obtido das repetições. Com a menor agulha existente no mercado somente foi possível obter gota com diâmetro de 2,28mm e massa de água de 0,006g. Para a obtenção de gotas com menores diâmetros foi usada uma micropipeta de volume variável, (Figura 3), que trabalha na faixa de
$10 \mu \mathrm{l}$ a $0,7 \mu \mathrm{l}$ mantendo-se as mesmas condições de realização do ensaio (gotejado nas mesmas condições de altura, número de gotas e modo de pesagem).

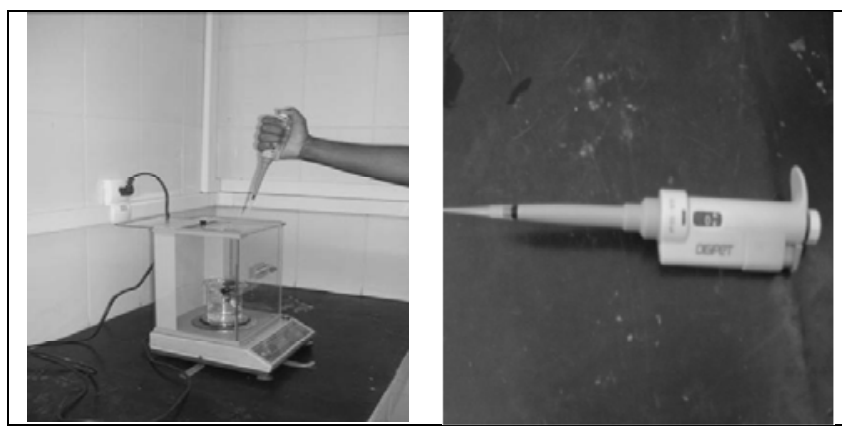

(a)

(b)

Figura 3 - Sistema para obter a massa da gota com micropipeta. a) processo de pesagem e b) micropipeta

Para determinação da massa e do diâmetro dos grânulos foi utilizado o sistema apresentado na Figura 4, que permitiu construir grânulos por gotejamento de água através de agulhas ou de micropipeta numa bandeja com farinha de trigo. O sistema é composto por um suporte metálico para fixar o frasco de soro fisiológico, gotejador, agulhas de várias aberturas, 04 bandejas com $20 \mathrm{~cm}$ de diâmetro e farinha de trigo. O suporte foi fixado de tal forma que a ponta da agulha ficasse a uma altura de $198 \mathrm{~cm}$ da bandeja contendo a farinha. Essa altura é igual à altura de queda das gotas do simulador de chuva utilizado. Para obtenção dos grânulos os seguintes passos foram executados:

- Regulou-se a altura de gotejamento e carga hidráulica (nível d’água no frasco) a cada inicio de ensaio;

- Em cada bandeja peneirou-se a farinha de trigo usando peneira de abertura de 1,18 $\mathrm{mm}$, até formar uma camada uniforme com espessura mínima de $2 \mathrm{~cm}$. A farinha deve estar no seu estado solto, para facilitar o amortecimento das gotas. Segundo Hudson (1964), o tempo entre o preparo da bandeja e a execução do ensaio não poderá exceder duas horas;

- Com velocidade constante, gotejou-se a água destilada sobre a farinha evitando-se a superposição das gotas. O total de 36 grânulos foram confeccionados, sendo 9 em cada bandeja; 
- Cobriram-se os grânulos com fina camada de farinha passada na peneira de $1,18 \mathrm{~mm}$, evitando-se assim a evaporação e assegurando que cada grânulo tenha o mesmo grau de contato com a farinha;

- Em seguida, as bandejas contendo os grânulos com farinha foram deixadas secar ao ar livre durante 24 horas e colocadas numa estufa à $60^{\circ} \mathrm{C}$, realizando-se pesagens diárias e retirando-as da estufa quando houver constância na massa, ou seja, quando os grânulos estiverem totalmente secos;

- Depois de secados em estufa, os grânulos foram separados por peneiramento, utilizando as peneiras 0,$710 ; 0,840 ; 1,00 ; 1,18$; 1,$41 ; 1,68 ; 2,00 ; 2,36 ; 2,83 ; 3,36$ e $4,75 \mathrm{~mm}$. Em seguida, foram levados novamente à estufa, na mesma temperatura anterior, para retirar a umidade adquirida durante o processo de peneiramento, e após estabilizada a umidade, obteve-se a massa total e a massa média dos grânulos retidos na respectiva peneira; A partir dos resultados obtidos anteriormente, pôde-se calcular para cada diâmetro médio de grânulo a relação entre a massa de água da gota e a massa do grânulo.

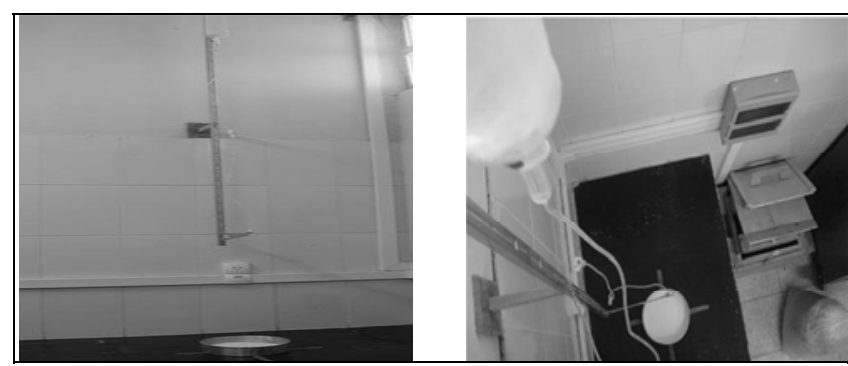

(a)

(b)

Figura 4 - Equipamento utilizado para determinar a massa e o diâmetro dos grânulos. a) vista frontal e

b) vista superior

b) Distribuição volumétrica das gotas de chuva do simulador

Para avaliar a influência da pressão e da abertura do disco na distribuição e no tamanho das gotas de chuva simulada foram realizados vários ensaios com o simulador ajustado para atingir pressões de 0,2, 0,4 e 0,6 bar. Para cada pressão variou-se a abertura do disco giratório em $5^{\circ}, 10^{\circ}$, $20^{\circ}, 30^{\circ}$ e $40^{\circ}$, a fim de obter intensidades diferentes, que ficaram na faixa de 38 a $420 \mathrm{~mm} / \mathrm{h}$.
O procedimento usado na realização do ensaio é descrito e ilustrado a seguir:

- Ajustar a posição do bico e abertura do disco, bem como centralizar a mesa de ensaio;

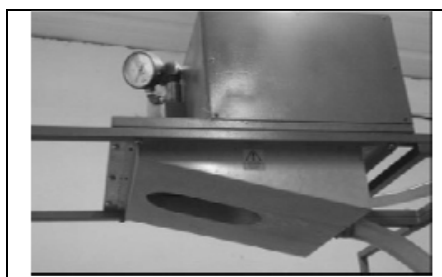

(a)

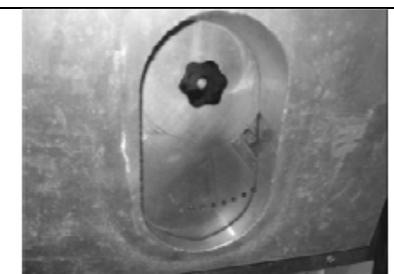

b)
Figura 5 - Ensaio com o simulador de chuvas empregando o método da farinha: (a) e (b) detalhe do mecanismo de ajuste da abertura do disco

- Realizar ensaio de precipitação para verificar se a intensidade desejada está sendo adequada;

- Passar a farinha de trigo fresca pela peneira de $1,18 \mathrm{~mm}$, preenchendo as 3 bandejas de área $0,28 \mathrm{~cm}^{2}$, com camada uniforme e mínima de $2 \mathrm{~cm}$ de espessura, visando-se o amortecimento das gotas e evitando-se perdas de massa de água no impacto da gota com a bandeja (Figura 6.a);

- Posicionar a bandeja sobre a mesa de ensaio e cobri-lá com tábua com tamanho superior ao da bandeja, evitando que respingue água na farinha (Figura 6.b);

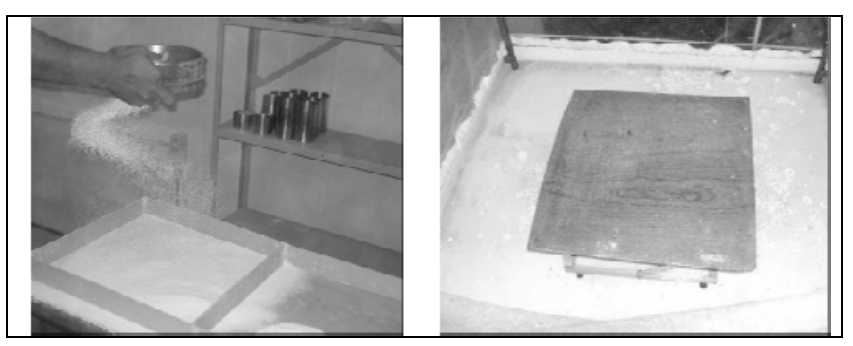

(a)

(b)

Figura 6. a) peneiramento da farinha $e$ (b) cobertura da bandeja.

- Ligar o simulador, ajustar a pressão e aguardar a estabilização da vazão;

- Retirar a tábua sobre a bandeja, expondo a farinha à precipitação durante 2 a 4 segundos aproximadamente, (Figura 7.a e 7.b); 


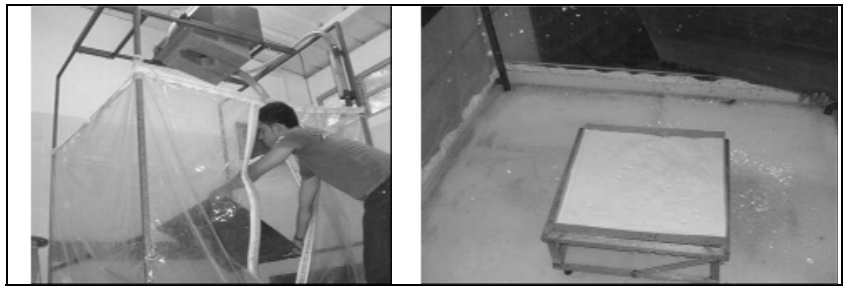

(a)

(b)

Figura 7. a) exposição da bandeja e

b) amostra exposta à chuva.

- Cobrir a bandeja com a tábua, desligando o simulador;

- Lançar uma fina camada de farinha de trigo, passada na peneira de $1,18 \mathrm{~mm}$, por toda a superfície da bandeja. Isto ajuda a minimizar a evaporação e assegurar que cada grânulo tenha o mesmo grau de contato com a farinha.

- Em seguida, as bandejas contendo os grânulos com farinha devem secar ao ar livre durante 24 horas e depois colocar na estufa à $60^{\circ} \mathrm{C}$, realizando-se pesagens diárias e retirando-as da estufa quando houver constância na massa, ou seja, quando os grânulos estiverem totalmente secos;

- Depois de secados em estufa, os grânulos devem ser separados por peneiramento, utilizando as peneiras 0,$710 ; 0,840 ; 1,00 ; 1,18$; 1,$41 ; 1,68 ; 2,00 ; 2,36 ; 2,83 ; 3,36$ e $4,75 \mathrm{~mm}$. Em seguida, devem ser levados novamente à estufa, na mesma temperatura anterior, para retirar a umidade adquirida durante $o$ processo de peneiramento e após a secagem devem ser pesados, obtendo-se a massa total e a massa média dos grânulos retidos na respectiva peneira (Figura $8 . a$ );

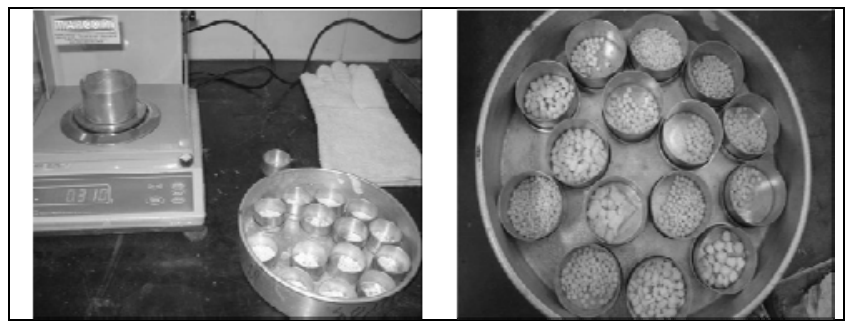

(a)

(b)

Figura 8. a) pesagem dos grânulos e

b) detalhe dos grânulos separados a serem contados.
- Depois da pesagem do material retido em cada peneira, faz-se a contagem do número de grânulos retidos em cada malha, ver detalhe dos grânulos na Figura 8.b. Peneiras menores que $0,710 \mathrm{~mm}$ não foram utilizadas, pois, os grânulos retidos nesta malha já são bastante pequenos e apresentam-se em grande quantidade, tornando difícil de serem manuseados.

- Usando os resultados da relação entre a massa de água e grânulo obtido da calibração e os dados de massa e número dos grânulos obtidos para cada classe de peneira, pode-se calcular a massa de água média da gota, considerando-a como esfera. O diâmetro pode ser obtido segundo equação 5:

$\mathrm{D} \equiv \sqrt[3]{\frac{6 \times \mathrm{m}}{\pi \times \rho}}$

Onde: D é o Diâmetro médio da gota $(\mathrm{mm})$; m é a Massa média da gota $(\mathrm{mg}) ; \rho$ é a Massa específica da água $\left(\mathrm{mg} / \mathrm{mm}^{3}\right)$.

- O volume de água por peneira pode ser obtido multiplicando-se o número de gotas ou grânulos pelo volume da gota relativo a cada peneira. O volume de cada gota foi calculado pela Equação 6:

$\mathrm{V} \equiv \frac{\pi \times \mathrm{D}^{3}}{6}$

Onde: V é o volume da gota de água, $\mathrm{mm}^{3}$.

- Acumulando-se o volume de água por peneira pode-se traçar um gráfico que expressa a relação entre o volume de água acumulado e o diâmetro médio de gota retida em cada peneira, sendo possível determinar-se o D50, ou seja, o diâmetro médio apresentado por $50 \%$ das gotas para dada intensidade.

\section{RESULTADOS E ANÁLISES}

a) Curva de calibração: Relação entre massa de água da gota e massa do grânulo (Mwgota/Mgrânulo): 
A Figura 9 apresenta a curva de calibração que expressa a relação entre a massa de água da gota e massa do grânulo formado (Mwgota/Mgrânulo), obtidos para diferentes tamanhos de grânulos. Embora haja considerável dispersão, a Equação 7 foi ajustada considerando todos os dados obtidos, donde se tem coeficiente de determinação de 0,67. Quando o primeiro dado obtido com micropipeta (ver Figura 9), que corresponde ao valor de $\mathrm{x}=0,0006$ e y $=0,8333$ é descartado, obtém-se melhor ajuste (Equação 8), com coeficiente de determinação de 0,88. Cabe ressaltar que gotas com diâmetro muito pequeno são extremamente difíceis de serem construídas, pois devido ao pequeno peso e á tensão superficial da água elas tem dificuldade de sair normalmente do bico da micropipeta. O emprego da vibração para desprendimento da gota pode afetar sobremaneira a sua massa. Muito provavelmente isto tenha ocorrido neste primeiro ponto.

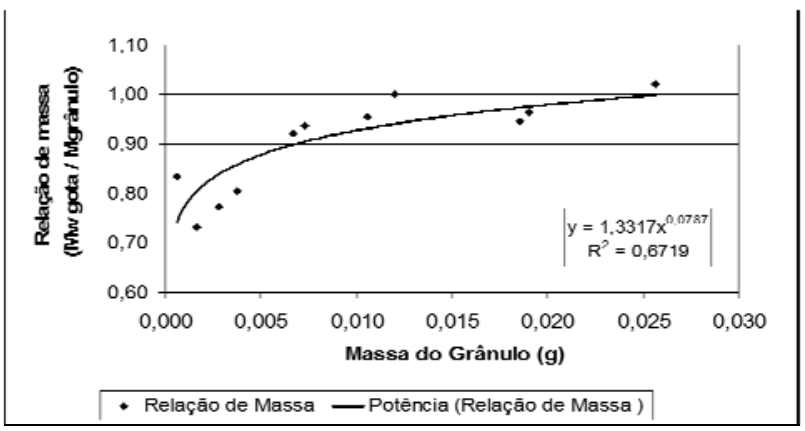

Figura 9 - Relação entre massa de água da gota e massa do grânulo formado.

$\frac{\mathrm{M}_{\mathrm{w}}}{\mathrm{M}_{\mathrm{g}}}=1,3317 \cdot \mathrm{M}_{\mathrm{g}}{ }^{0,0787}$

$\frac{\mathrm{M}_{\mathrm{w}}}{\mathrm{M}_{\mathrm{g}}}=1,6015 \cdot \mathrm{M}_{\mathrm{g}}^{0,1192}$

Onde $\mathrm{M}_{\mathrm{w}}$ é a massa da gota e $\mathrm{M}_{\mathrm{g}}$ é a massa do granulo.

Segundo Hudson (1964), a relação entre as massas não é linear, no entanto, gotas maiores que $4 \mathrm{~mm}$ de diâmetro tendem a ter relação linear entre massas, mas gotas de tamanho menores não.

b) Distribuição volumétrica das gotas de chuva do simulador

Para efeito de ilustração a Tabela 01 apresenta resultados típicos obtidos de ensaios realizados com o simulador de chuva, ajustado para pressão de
0,2 bar e abertura de disco giratório de $5^{\circ}$. Os resultados obtidos são os números de grânulos em cada peneira e a massa total deles. Dividindo a massa total pelo número de grânulos, encontra-se a massa unitária do grânulo por peneira. A massa do grânulo multiplicada pela relação entre as massas de água/grânulo dada pela Equação 8, obtém-se a massa média de água da gota, que quando utilizada na Equação 5 fornece o diâmetro da gota. Com os resultados de diâmetro da gota e volume acumulado traça-se a curva de distribuição do tamanho das gotas, a qual permite determinar o diâmetro médio das gotas (D50), que ó diâmetro correspondente ao volume acumulado de 50\%. A figura 09 mostra curvas de distribuição do tamanho das gotas obtidas para a abertura de disco de $5^{\circ}$ e pressão de $0,2,0,4$ e 0,6 bar. A tabela 01 apresenta também os dados referentes ao volume de cada gota, o volume total das gotas em cada peneira, o percentual volumétrico de cada classe e o percentual volumétrico acumulado da gota em relação ao ensaio. Na figura 10 á apresentado a curva de volumes acumulados para as pressões 0,2, 0,4 e 0,6 bar, necessárias para a determinação do D50 para curva.

A Figura 11 apresenta os resultados de D50 obtidos para o simulador estudado, com todas as pressões trabalhadas $(0,2,0,4$ e 0,6 bar $)$ e aberturas do disco $\left(5^{\circ}, 10^{\circ}, 20^{\circ}, 30^{\circ}\right.$ e $\left.40^{\circ}\right)$. Obteve-se que para a mesma pressão, o aumento da abertura da placa defletora resulta, em geral, em aumento do diâmetro médio da gota, e para a mesma abertura, aparentemente, o aumento da pressão de serviço resulta em redução do diâmetro médio da gota, pois as gotas são pulverizadas, resultando em maior fracionamento das mesmas. Este comportamento também pode estar associado ao efeito da placa giratória, pois conforme acontece o aumento da abertura da placa acontece a aproximação dos valores do diâmetro médio das gotas. Isto pode ser observado de forma marcante para abertura de $40^{\circ}$, onde há pouca variação do diâmetro médio para diferentes pressões. Também, observa-se pequena variação no tamanho médio das gotas de chuva simulada, para pressões de serviço de 0,2 e 0,4 bar e aberturas de disco superior a $10^{\circ}$. Diante do observado, pode-se inferir que existe maior influência da abertura do disco giratório que da própria pressão na geração dos diâmetros das gotas.

A influência da abertura do disco pode ser confirmada analisando o gráfico de calibração da precipitação (Figura 12), a intensidade sofre forte variação com a mudança de abertura de disco, com o aumento da pressão $(0,2,0,4$ e 0,6 bar) existe uma 
Tabela 01 - Resultados obtidos a partir dos ensaios realizados no simulador de chuvas para a pressão de 0,2 bar e abertura de disco de $5^{\circ}$.

\begin{tabular}{|l|l|l|l|l|l|l|l|l|l|l|l|l|}
\hline \# Peneira (mm) & Pó & 0,71 & 0,84 & 1,00 & 1,18 & 1,41 & 1,68 & 2,00 & 2,36 & 2,83 & 3,36 & 4,75 \\
\hline No Granulos & 0 & 1263 & 1231 & 795 & 1070 & 366 & 388 & 200 & 102 & 184 & 25 & 0,00 \\
\hline $\begin{array}{l}\text { Massa Total do Gra- } \\
\text { nulo (g) }\end{array}$ & 0,000 & 0,436 & 0,723 & 0,710 & 1,484 & 0,913 & 1,758 & 1,514 & 1,523 & 5,519 & 0,911 & 0,000 \\
\hline $\begin{array}{l}\text { M. por Granulo 10-3 } \\
\text { (g) }\end{array}$ & 0,0 & 0,3 & 0,6 & 0,9 & 1,4 & 2,5 & 4,5 & 7,6 & 14,9 & 30,0 & 36,4 & 0,0 \\
\hline Relação das Massas & 0,0000 & 1,000 & 0,6500 & 0,7325 & 0,7700 & 0,7883 & 0,9758 & 0,9656 & 0,9458 & 0,9542 & 0,9598 & 0,0000 \\
\hline M. da Gota 10-3 (g) & 0,0 & 0,3 & 0,4 & 0,7 & 1,1 & 2,0 & 4,4 & 7,3 & 14,1 & 28,6 & 35,0 & 0,0 \\
\hline V. da Gota 10-3 (cm $\left.{ }^{3}\right)$ & 0,0 & 0,3 & 0,38 & 0,7 & 1,1 & 2,0 & 4,4 & 7,3 & 14,1 & 28,6 & 35,0 & 0,0 \\
\hline $\begin{array}{l}\text { Vol. Total das Gotas } \\
\text { na classe (cm }{ }^{3} \text { ) }\end{array}$ & 0,00 & 0,44 & 0,47 & 0,52 & 1,14 & 0,72 & 1,72 & 1,46 & 1,44 & 5,27 & 0,87 & 0,00 \\
\hline D. da Gota (mm) & 0,00 & 0,87 & 0,90 & 1,08 & 1,27 & 1,55 & 2,04 & 2,41 & 3,00 & 3,80 & 4,06 & 0,00 \\
\hline$\%$ Vol & 0,00 & 3,10 & 3,35 & 3,70 & 8,13 & 5,12 & 12,21 & 10,41 & 10,25 & 37,49 & 6,22 & 0,00 \\
\hline \% Vol. Acumulado & 0,00 & 3,10 & 6,45 & 10,15 & 18,29 & 23,41 & 35,62 & 46,03 & 56,29 & 93,78 & 100,0 & 0,0 \\
\hline Coef. de Arrasto (C2) & 0,000 & 0,536 & 0,518 & 0,434 & 0,369 & 0,302 & 0,232 & 0,196 & 0,158 & 0,125 & 0,117 & 0,000 \\
\hline
\end{tabular}

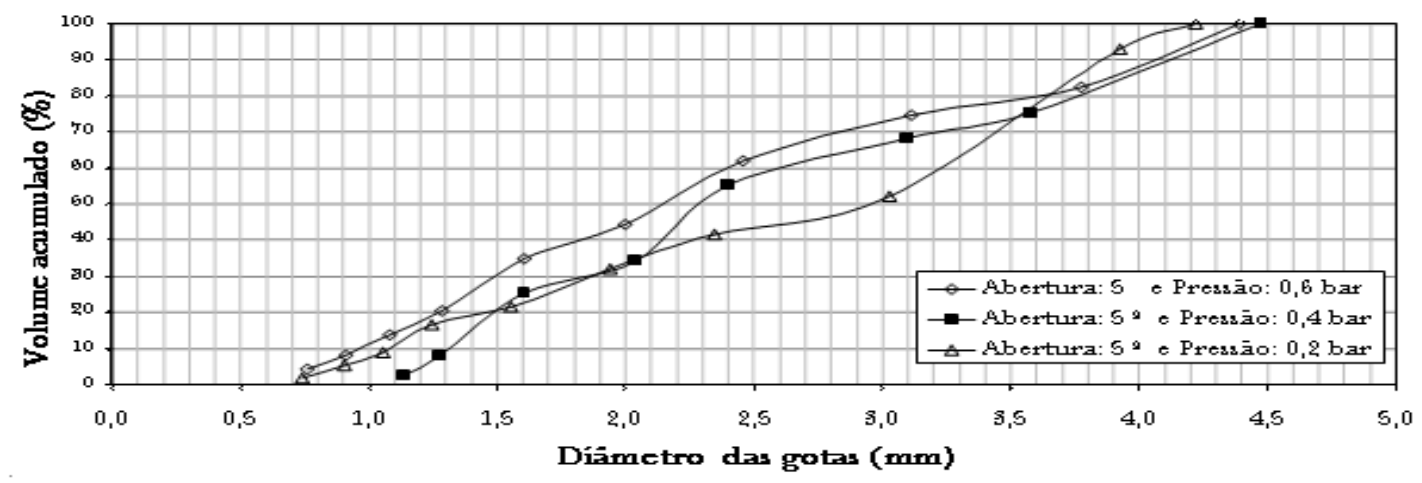

Figura 10 - Diâmetro médio da gota (D50) para as pressões de 0,2, 0,4 e 0,6 bar e abertura de disco de $5^{\circ}$.

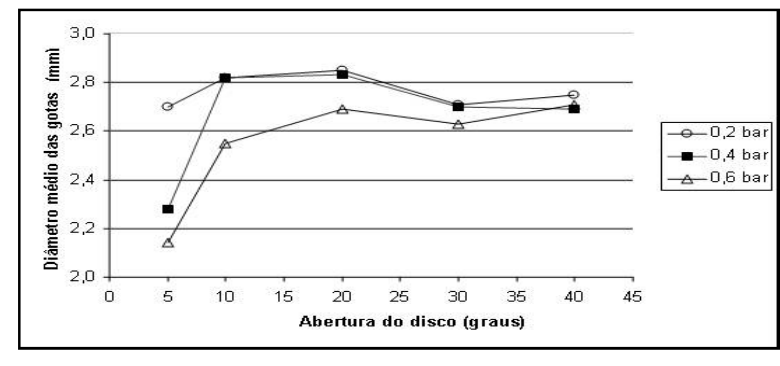

Figura 11 - Valores de D50 obtidos para o simulador de chuvas FL3 da Armfield com diferentes pressões (0,2, 0,4 e 0,6 bar) e aberturas do disco $\left(5^{\circ}, 10^{\circ}, 20^{\circ}, 30^{\circ}\right.$ e $\left.40^{\circ}\right)$.

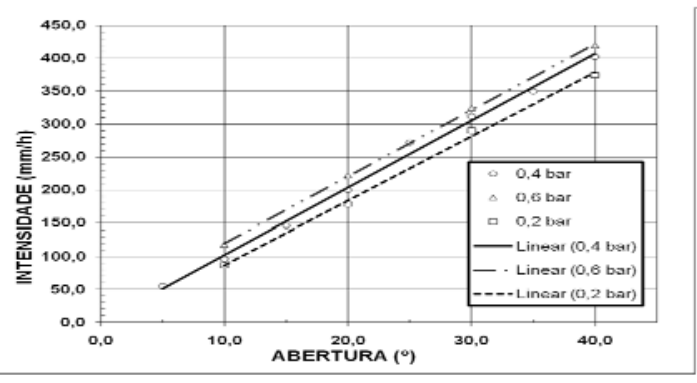

Figura 12 - Gráfico da variação da intensidade para o simulador de chuvas FL3 da Armfield com diferentes pressões $\left(0,2,0,4\right.$ e 0,6 bar) e aberturas do disco $\left(5^{\circ}, 10^{\circ}\right.$, $20^{\circ}, 30^{\circ}$ e $40^{\circ}$ ) com bocal 01. 
pequena variação da intensidade, o que determina as retas paralelas próximas.

Para efeitos construtivos, em simuladores de chuva sem o sistema de placa giratória com aberturas e que trabalhem com bico pressurizado, se observará que a mudança de pressão terá pouco efeito na mudança na intensidade e no diâmetro da gota. Neste sentido a forma de obter faixa maior de operação do simulador seria mediante uma mudança na forma bico, que representa a necessidade de avaliação para cada tipo de bocal, no aspecto de intensidade e diâmetro de gota gerado.

\section{CONCLUSÕES}

A aplicação do método da farinha permitiu avaliar o funcionamento do simulador, mediante a obtenção dos valores de diâmetro médio das gotas de chuva simulada para diferentes pressões de serviço e abertura de disco, importante para o processo de calibração do equipamento. Observouse que a abertura da placa de ajuste da intensidade da precipitação afeta o diâmetro médio das gotas de chuva de forma significativa, e que a pressão têm pouca influência no diâmetro. Este fenômeno também foi observado na variação da intensidade. A importância da avaliação na determinação do diâmetro médio se deve a sua relação com a força de impacto, determinando menor ou maior poder de desagregação e erosão do solo, além dos fatores de composição, uso e declividade do solo.

Foi possível estabelecer o detalhamento do procedimento para execução do ensaio de determinação do diâmetro médio das gotas com o método da farinha a fim de propor a padronização do ensaio. Apesar de ser um método trabalhoso, apresenta-se como alternativa interessante, pois não exige equipamentos sofisticados e de alto custo no seu emprego. Neste sentido o método da farinha pode ser bastante útil para avaliação de funcionamento de simuladores e na determinação das variáveis que caracterizam a erosividade da chuva natural e simulada.

\section{REFERÊNCIA}

ALVES SOBRINHO, T.; FERREIRA, P. A. e PRUSKY, F. F. Desenvolvimento de um infiltrômetro de aspersão portátil.
Revista Brasileira de Engenharia Agrícola e Ambiental, Campina Grande, v. 6, n. 2, 2002.

ARMFIELD. Manual de uso do simulador de chuvas. Inglaterra: Armfield, 1998.

ATTLE, J. R.; ONEY, D. e SWENSON, R. A. Aplications of image analysis. American Laboratory, Abril de 1980.

CRUVINEL, P. E.; MINATEL, E. R.; MUCHERONI, M. L.; VIEIRA, S. R. ; CRESTANA, S. An Automatic Method Based on Image Processing for Measurements of Drop Size Distribution from Agricultural Sprinklers. Anais do IX SIBIGRAPI, outubro de 1996.

EIGEL, J. D.; MOORE, I. D. A simplified technique for measuring riandrop size and distribuition. Transactions of the ASAE, $\mathrm{v}$. 26, n. 4, p. 1079-1084, 1983.

FOSTER, G. R.; McCOOL, D. K.; RENARD, K. G.; MOLDENHAUER, W. C. Conversion of the universal soil loss equation to SI units. Journal of Soil and Water Conservation, Ankeny, v. 36, n. 6, p. 355-359, 1981.

GUNN, R. e KINZER, G.D. The terminal velocity of fall for water droplets in stagnant air. Journal Meteorology. v.6, p 243248, 1949.

GUY, B. T.; DICKINSON, W. T.; RUDRA, R. P. The roles of rainfall and runoff in the sediment transport capacity of interril flow. Transactions of the ASAE, St. Joseph, v. 30, n. 5, p. 1378-1385, Sept./Oct. 1987.

HALL, M. J. Use of the stain method in determining the dropsize distribution of coarse liquid spray. Transaction of the ASAE, v. 13, n. 1, p. 33-37, 1970.

HUDSON, N. W. The flour pellet method for measuring the size of raindrops, Department of conservation, Research Bulletin, Salisbury, n.4, 1964.

JOSS, J. e WALDVOGEL, A. Raindrop size distribution and sampling size errors. Journal of the Atmospheric Sciences, $p$. 566-569, 1969

KINCAID, D.C.; SOLOMON, K. H.; OLIPHANT, J. C. Drop size distributions for irrigation sprinkler. Transactions of the ASAE, v. 39 , n. 3, p. $839-845$, 1996. In press.

$\mathrm{KOHL}, \mathrm{R}$. A. Drop size distribution from a medium sized agricultural sprinkler. Transactions of the ASAE, v. 17, n. 4, p. 69069, 1974.

RIBEIRO, B. T. Energia cinética de gotas de chuva simulada e energia ultra-sônica na desagregação de um Cambissolo. 
2006. 65f. Dissertação (Mestrado) - Universidade Federal de Lavras, 2006, 65 p.

TOKAY, A.; WOLFF, K. R.; BASHOR, P.; DUR

SUN, O. On the measurement errors of the Joss-Waldvogel disdrometer. Preprints, 31st International Conference on Radar Meteorology. Seattle, American Meteoroly Society, p. 437440, 2003.

WISCHMEIER, W. H.; SMITH, D. D. Rainfall energy and its relationships to soil loss. Transactions of the American Geophysical Union, Washington, v. 39, n. 2, p. 285-291, 1958.

\section{Studying the Performance of a Rainfall Simulator Using the Flour Method}

\section{ABSTRACT}

This paper analyzes the effect of the operational parameters working pressure and disc plate opening of a rainfall simulator on the droplet size distribution and rainfall kinetic energy using the flour method. Furthermore, this paper describes in detail the experimental procedure adopted and make some proposals to standardize the method. Although laborious, the flour method was considered appropriate for determination of the D50 in different situations of rainfall simulator operation with a pressurized nozzle and rotary plate. The results showed that the opening of the plate significantly affects the average diameter of the drops and that the water pressure has a less significant effect. A similar behavior was observed when analyzing the intensity of the produced rain, in which the opening of the plate plays an important role.

Key-words: simulated rainfall; diameter drop; kinetic energy. 